\title{
Vegetation patterns influence on soil microbial biomass and functional diversity in a hilly area of the Loess Plateau, China
}

\author{
Chanjuan Hu • Bojie Fu • Guohua Liu • Tiantian Jin • \\ Lei Guo
}

Received: 5 September 2009 /Accepted: 21 February 2010/Published online: 24 March 2010

(C) Springer-Verlag 2010

\begin{abstract}
Purpose Shifts of microbial biomass and functional diversity under different vegetation patterns can impact the soil processes, and the specific knowledge about this can be used to develop sound vegetation restoration strategies. This study was devoted to examine the effects of different vegetation patterns on microbial biomass and functional diversity and explore the relationship between soil erosion and soil microbial properties under typical erosion conditions of the semiarid hilly area of the Loess Plateau, China.

Materials and methods Soil samples were collected from the Yangjuangou catchment near Yan'an City, northern Shaanxi province, China. Four types of slopes, each with different vegetation pattern, were sampled, including $\mathrm{F}$ (forest planted by human), G (grass), G-F-G (grass on the upper and lower slopes and forest on the middle slope), and $\mathrm{F}-\mathrm{G}-\mathrm{F}$ (forest on the upper and lower slopes and grass on the middle slope). Top soil samples $(0-10 \mathrm{~cm})$ from each of the four slopes were analyzed for their physicochemical properties, microbial biomass, and functional diversity. The microbial biomass was analyzed using the fumigationextraction method and microbial functional diversity using the community-level physiological profile method.

Results and discussion The analysis of variance revealed a trend of increasing nutrient concentrations and soil microbial biomass nitrogen in the G-F-G soil samples. However, the $\mathrm{F}-\mathrm{G}-\mathrm{F}$ slope had the highest microbial biomass carbon, with an average of $289 \mathrm{mg} \mathrm{kg}^{-1}$ and had the highest
\end{abstract}

Responsible editor: Chengrong Chen

C. $\mathrm{Hu} \cdot$ B. $\mathrm{Fu}(\bowtie) \cdot \mathrm{G}$. Liu $\cdot$ T. Jin $\cdot$ L. Guo

State Key Laboratory of Urban and Regional Ecology,

Research Center for Eco-Environmental Sciences,

Chinese Academy of Sciences,

P.O. Box 2871, Beijing 100085, People's Republic of China

e-mail: bfu@rcees.ac.cn average well color development values (up to $120 \mathrm{~h}$ of incubation), which is used as an indicator of microbial activity. Mean values of Shannon diversity $\left(\mathrm{H}^{\prime}\right)$, which are indicative of soil microbial functional diversity, ranged from only 2.75 for $F$ to 2.82 for $F-G-F$. Principal component analysis showed that the four vegetation patterns had differences that are consistent with different carbon substrate utilization patterns. The greatest differences in single-carbon substrate utilization were between $\mathrm{F}-\mathrm{G}-\mathrm{F}$ and $\mathrm{F}$ and between $\mathrm{F}-\mathrm{G}-\mathrm{F}$ and $\mathrm{G}-\mathrm{F}-\mathrm{G}$.

Conclusions The $\mathrm{F}-\mathrm{G}-\mathrm{F}$ vegetation pattern was the best pattern for restoring soils on sloping land in terms of improving soil microbial biomass carbon, soil microbial functional diversity, and activity. Soil erosion processes might have an indirect effect on soil microbial biomass through its influence on soil physicochemical properties in the typical erosion-prone region of the Loess Plateau, China.

Keywords Community level physiological profile .

Loess Plateau - Microbial biomass - Microbial diversity . Soil erosion $\cdot$ Vegetation restoration

\section{Introduction}

Microorganisms are an important part of the soil ecosystem. They are involved in forming the structure of soil (Harris and Birch 1989), directly influence ecosystem stability and soil fertility (Smith and Papendick 1993); thus, they play crucial roles in biogeochemical cycling and ecosystem functioning (Morin and McGrady-Steed 2004; Bell et al. 2005; Green and Bohannan 2006). Soil microorganisms are sensitive to changes in land-use patterns, management treatments, and tillage practices (Steenwerth et al. 2002; Bucher and Lanyon 2005; Ge et al. 2008). Soil biological 
and biochemical properties such as microbial biomass, microbial community composition, and microbial functional diversity are often measured to provide immediate and accurate information about small changes in soils (Pascual et al. 2000; He et al. 2008).

Many studies have found that microbial biomass is a sensitive indicator of changes resulting from agronomic practices and other perturbations of the soil ecosystem (Doran 1987; Smith and Paul 1990). Thus, microbial biomass is a valuable tool for understanding changes in soil properties and the degree of soil degradation. Soil microbial community composition and diversity are also important indicators used to assess ecological processes, structure, and soil functions (Harris 2003; Nannipieri et al. 2003; He et al. 2009). However, the conventional methods provide limited information regarding the functional diversity of the microbial community. The developed community-level physiological profile method now provides a rapid and effective procedure to analyze soil microbial communities (Zak et al. 1994; Zhang and $\mathrm{Xu}$ 2008). Its application through the BIOLOG system has been used to measure the microbial communities under a variety of conditions such as cultivated and uncultivated soil (Yan et al. 2000), various crop types and rotation schemes (Garland 1996; Lupwayi et al. 1998), grasslands (Zak et al. 1994), different tree species (Grayston and Campbell 1996), and boreal plain forests (White et al. 2005).

In the hilly areas of the Loess Plateau, China, soil erosion is a serious problem. It reduces soil productivity, causes irreversible soil and nutrient loss, and is regarded as one of the most widespread forms of land degradation (Gobin et al. 2004). The Chinese government has provided huge amounts of funds and established incentive policies to discourage farmers from cultivation of short-term crops on the sloping land and instead to plant woodland shrubbery or grass to control soil and water loss and to improve environmental quality. Studies have shown that the vegetation restoration practices are effective in preventing soil erosion, reducing water and nutrient losses, and protecting the environment (Fu et al. 2004; Zheng 2006). In addition, the increase in vegetation could also positively affect the soil microorganisms (Xu et al. 2009).

There are clear relationships among microbial diversity, soil and plant quality, and ecosystem sustainability (Doran et al. 1994; Hill et al. 2000). The existing studies have shown that vegetation restoration can markedly improve soil physical and chemical properties in comparison with bare land (Wang et al. 2004) and that soil microbial biomass is higher under vegetation than under bare land, which increases over time with revegetation (Harris 2003). The effects of different land-use types and vegetation restoration practices on soil physicochemical properties and soil microbial biomass have also been reported (Gong et al. 2004; Xue et al. 2008) in the Loess Plateau of China.
However, there has been a lack of studies for the specific relationships between different hill-slope vegetation patterns and soil microorganism abundance and activity. The vegetation pattern is important for ecosystem restoration and soil erosion control in the study area. It can result in different erosion processes and exert different effects on soil ecosystem. In this study, we selected a range of vegetation patterns including forest, grass, and combinations of forest and grass in different slope positions on the hill slopes. The objectives were: (1) to examine soil microbial biomass and functional diversity under different vegetation patterns and (2) to understand the relationship of soil erosion and soil microbial properties.

\section{Materials and methods}

\subsection{Study site}

The study was conducted in the Yangjuangou catchment $\left(36^{\circ} 42^{\prime} \mathrm{N}, 109^{\circ} 31^{\prime} \mathrm{E}\right)$, which is located near Yan'an City, northern Shaanxi province, China. This catchment belongs to a secondary tributary of the Yanhe River, and the study area is typical of the erosion-prone Loess Plateau. The catchment has an area of $2.02 \mathrm{~km}^{2}$ and elevation between 1,025 and $1,250 \mathrm{~m}$ above mean sea level. The mean annual rainfall is $550 \mathrm{~mm}$, and the rainfall patterns are highly variable both monthly and annually. Seventy percent of the rainfall occurs between July and September. Soils in the study area are Calcaric Cambisols, which were uniformly textured and weakly structured. Therefore, they are readily susceptible to soil erosion ( $\mathrm{Li}$ et al. 1999). The natural vegetation in the area is mostly shrubby grassland, including Stipa bungeana, Lespedeza daurica, Heteropappus altaicus, Artemisia gmelinii, etc. Robinia pseudoacacia is the main species of forest planted by human when annual crops are no longer cultivated on the slopes.

\subsection{Soil sampling}

Annual cropping on the sloping land was abandoned for perennial vegetation restoration was begun in the 1980s in this catchment. We selected four hill slopes with different vegetation patterns, including $R$. pseudoacacia forest $(\mathrm{F})$, grass $(\mathrm{G})$, grass on the upper and lower slope and $R$. pseudoacacia forest on the middle slope $(\mathrm{G}-\mathrm{F}-\mathrm{G})$, and $R$. pseudoacacia forest on the upper and lower slope and grass on the middle slope $(\mathrm{F}-\mathrm{G}-\mathrm{F})$. The altitude of area ranged from 1,138 to $1,250 \mathrm{~m}$, and the slope degree ranged from $9^{\circ}$ to $29^{\circ}$. On each of the four slopes, we established three transects from the hilltops to the hilltoes. Sampling sites were spaced every 35-45 $\mathrm{m}$ along the transects. Each slope had six sampling sites, except for G-F-G, which had 
five. Each sampling site included three sample plots (one along each of the transects). Thus, each slope had 15 or 18 sampling plots. The area of each sampling site was about $200 \mathrm{~m}^{2}$, and the area of each sample plot was $25 \mathrm{~m}^{2}$.

Five soil cores $(0-10 \mathrm{~cm}$ depth, $3.5 \mathrm{~cm}$ diameter) were collected from each sampling plot in August 2007 and stored in insulated and sealed plastic bags to prevent moisture loss. The soil samples were gently mixed and sieved through a 2-mm screen mesh under field-moisture conditions. They were then kept on ice for transport to the laboratory and stored at $4^{\circ} \mathrm{C}$. Subsamples of each soil were air-dried for chemical analysis. Additional soil samples (except for one site under toe slope of $F-G-F$ that was not sampled) were collected from the same sites and air-dried for ${ }^{137} \mathrm{Cs}$ analysis.

\subsection{Analysis of soil physicochemical properties}

Soil water content (SWC) in each sample was determined by weight loss after heating at $105^{\circ} \mathrm{C}$ for $24 \mathrm{~h}$ and expressed as a percentage of dry weight. Bulk density (BD) was estimated using the oven-dried soil mass and volume of the sample. Soil $\mathrm{pH}$ and electrical conductivity (EC) were measured at a soil-to-water ratio of 1:2.5. Soil organic carbon (SOC) was determined by the $\mathrm{K}_{2} \mathrm{Cr}_{2} \mathrm{O}_{7}$ titration method after digestion ( $\mathrm{Lu}$ 1999). Soil total nitrogen (TN) was determined by the semi-micro Kjeldahl method (Bremner 1996).

\section{$2.4{ }^{137} \mathrm{Cs}$ analysis}

The concentration of ${ }^{137} \mathrm{Cs}$ was measured using a hyperpure coaxial Ge detector coupled to a multi-channel analyzer ( $\mathrm{Li}$ et al. 2003). Samples were detected at the $662 \mathrm{keV}$ peak over a counting time of $80,000 \mathrm{~s}$, which provided an analytical precision of $\pm 6 \%$ for ${ }^{137} \mathrm{Cs}$.

\subsection{Analysis of microbial biomass}

Soil microbial biomass carbon $\left(\mathrm{C}_{\text {mic }}\right)$ was measured using the fumigation-extraction method as described in Vance et al. (1987). Concentrations of $\mathrm{K}_{2} \mathrm{SO}_{4}$-extracted $\mathrm{C}$ in $\mathrm{CHCl}_{3}$ fumigated and non-fumigated soils were determined using a UV-Persulfate automated carbon analyzer (TekmarDohrmann Co. USA) $\left(K_{\mathrm{C}}=0.45\right)$. Soil microbial biomass nitrogen $\left(\mathrm{N}_{\text {mic }}\right)$ was measured using the Kjeldahl digestion method as described in Brookes et al. (1985) $\left(K_{\mathrm{N}}=0.54\right)$.

\subsection{BIOLOG procedure}

The functional diversity of the soil microbial community was measured using BIOLOG-ECO plates (Biolog Inc., Hayward, CA). The method used for inoculum preparation was adapted from Zak et al. (1994) and Staddon et al. (1998). Average well color development (AWCD), calculated as the average optical density across all wells per plate, was used as an indicator of general microbial activity. BIOLOG data at $96 \mathrm{~h}$ of incubation were used to calculate the Shannon diversity index (the relative contribution of the optical density of positive wells on BIOLOG plates) as a measure of catabolic diversity (Begon et al. 1990): $H^{\prime}=-\sum_{i=1}^{S} P_{i} \log P_{i}, \quad$ where $\quad P_{i}=\frac{C-R}{\sum(C-R)} . H^{\prime}$ represented substrate diversity, and $P_{i}$ was the ratio of the activity on a particular substrate to the sum of the activities on all substrates.

\subsection{Data analysis}

SPSS version 11.0 and Canoco version 4.5 software were used for data analysis. The significance of differences in soil properties among the four vegetation patterns were determined by the univariate ANOVA. Differences at the $P<0.05$ level were considered to be statistically significant using the least significant difference (LSD) test. Principal component analysis was conducted for the BIOLOG data. Correlation analysis was used to elucidate the relationships between soil microbial properties, soil physicochemical properties, and degree of soil erosion.

\section{Results}

3.1 Soil physicochemical properties and soil erosion under different vegetation patterns

Physical and chemical analyses of the soil samples showed several significant differences in soil properties among the four vegetation patterns $(P<0.05$; Table 1$)$. For the $0-10 \mathrm{~cm}$ surface soil, G-F-G had higher SOC, TN, and $\mathrm{pH}$ than those of the other vegetation patterns, and the grass vegetation $(\mathrm{G})$ had the highest values of EC, BD, and SWC.

The concentration of ${ }^{137} \mathrm{Cs}$ was used to estimate the degree of soil erosion. Highly eroded soils have low concentrations of ${ }^{137} \mathrm{Cs}$. The concentration of ${ }^{137} \mathrm{Cs}$ varied significantly between the different slope positions (Fig. 1). The value of ${ }^{137} \mathrm{Cs}$ was higher at the summit and on the lower slope for the $\mathrm{G}-\mathrm{F}-\mathrm{G}$ and $\mathrm{F}-\mathrm{G}-\mathrm{F}$ sites. The $\mathrm{F}$ and $\mathrm{G}$ sites had higher ${ }^{137} \mathrm{Cs}$ content on the middle slope and lower slope.

3.2 Soil microbial biomass under different vegetation patterns

There were statistically significant differences in $\mathrm{C}_{\text {mic }}$ among the mean values of the four vegetation patterns $(P<0.05)$. The $\mathrm{F}-\mathrm{G}-\mathrm{F}$ slope had the highest $\mathrm{C}_{\text {mic }}$, with an average of $289 \mathrm{mg} \mathrm{kg}^{-1}$. The lowest value was $170 \mathrm{mg} \mathrm{kg}^{-1}$, 
Table 1 Soil physicochemical properties under four vegetation patterns
Numbers 1 to 6 indicate different sampling sites from the summit to the toe slope along the hill slope. Different capital letters in the same column indicate significant differences at the 0.05 level among the vegetation patterns

$F$ forest, $G$ grass, $G-F-G$ grass on the upper and lower slopes and forest on the middle slope, $F-G-F$ forest on the upper and lower slopes and grass on the middle slope, $S O C$ soil organic carbon, $T N$ total nitrogen, $E C$ electrical conductivity, $B D$ bulk density, $S W C$ soil water content

\begin{tabular}{|c|c|c|c|c|c|c|c|}
\hline Vegetation pattern & Site & $\begin{array}{l}\mathrm{SOC} \\
\left(\mathrm{gkg}^{-1}\right)\end{array}$ & $\begin{array}{l}\mathrm{TN} \\
\left(\mathrm{gkg}^{-1}\right)\end{array}$ & $\mathrm{pH}$ & $\begin{array}{l}\mathrm{EC} \\
\left(\mu \mathrm{scm}^{-1}\right)\end{array}$ & $\begin{array}{l}\mathrm{BD} \\
\left(\mathrm{gcm}^{-3}\right)\end{array}$ & $\begin{array}{l}\text { SWC } \\
(\%)\end{array}$ \\
\hline \multirow[t]{9}{*}{$\mathrm{F}$} & $\mathrm{F} 1$ & 5.24 & 0.60 & 8.15 & 158.03 & 1.10 & 3.91 \\
\hline & $\mathrm{F} 2$ & 8.54 & 0.85 & 8.12 & 192.47 & 1.14 & 6.48 \\
\hline & F3 & 7.29 & 0.71 & 8.16 & 164.83 & 1.10 & 5.18 \\
\hline & $\mathrm{F} 4$ & 6.46 & 0.67 & 8.31 & 147.03 & 1.17 & 5.43 \\
\hline & F5 & 5.27 & 0.51 & 8.22 & 148.33 & 1.20 & 4.37 \\
\hline & F6 & 5.03 & 0.49 & 8.32 & 130.57 & 1.27 & 4.24 \\
\hline & Mean & 6.31 & 0.64 & 8.21 & 156.88 & 1.16 & 4.94 \\
\hline & S.D. & 1.40 & 0.13 & 0.09 & 20.94 & 0.06 & 0.95 \\
\hline & Significant difference & $\mathrm{B}$ & $\mathrm{A}$ & $\mathrm{A}$ & $\mathrm{A}$ & $\mathrm{B}$ & $\mathrm{C}$ \\
\hline \multirow[t]{9}{*}{ G } & G1 & 4.25 & 0.50 & 8.13 & 177.00 & 1.21 & 9.55 \\
\hline & G2 & 5.51 & 0.56 & 8.16 & 178.90 & 1.26 & 9.82 \\
\hline & G3 & 5.47 & 0.58 & 8.14 & 152.13 & 1.24 & 8.04 \\
\hline & G4 & 6.13 & 0.61 & 8.11 & 174.33 & 1.23 & 8.82 \\
\hline & G5 & 6.67 & 0.67 & 8.13 & 171.47 & 1.26 & 8.57 \\
\hline & G6 & 6.63 & 0.65 & 8.05 & 289.97 & 1.28 & 9.02 \\
\hline & Mean & 5.78 & 0.59 & 8.12 & 190.63 & 1.25 & 8.97 \\
\hline & S.D. & 0.91 & 0.06 & 0.04 & 49.61 & 0.02 & 0.65 \\
\hline & Significant difference & $\mathrm{B}$ & $\mathrm{A}$ & $\mathrm{B}$ & $\mathrm{A}$ & $\mathrm{A}$ & A \\
\hline \multirow[t]{8}{*}{$\mathrm{G}-\mathrm{F}-\mathrm{G}$} & $\mathrm{G}-\mathrm{F}-\mathrm{G} 1$ & 8.02 & 0.77 & 8.28 & 153.93 & 1.32 & 6.06 \\
\hline & $\mathrm{G}-\mathrm{F}-\mathrm{G} 2$ & 6.04 & 0.56 & 8.29 & 153.47 & 1.15 & 8.85 \\
\hline & $\mathrm{G}-\mathrm{F}-\mathrm{G} 3$ & 10.99 & 0.99 & 8.28 & 188.70 & 1.14 & 8.95 \\
\hline & $\mathrm{G}-\mathrm{F}-\mathrm{G} 4$ & 7.20 & 0.61 & 8.31 & 154.53 & 1.17 & 8.19 \\
\hline & G-F-G5 & 7.96 & 0.70 & 8.28 & 138.23 & 1.10 & 5.82 \\
\hline & Mean & 8.04 & 0.72 & 8.29 & 157.77 & 1.18 & 7.57 \\
\hline & S.D. & 1.83 & 0.17 & 0.01 & 18.59 & 0.09 & 1.52 \\
\hline & Significant difference & $\mathrm{A}$ & A & $\mathrm{A}$ & $\mathrm{A}$ & $\mathrm{AB}$ & $\mathrm{AB}$ \\
\hline \multirow[t]{9}{*}{$\mathrm{F}-\mathrm{G}-\mathrm{F}$} & $\mathrm{F}-\mathrm{G}-\mathrm{F} 1$ & 5.81 & 0.65 & 8.17 & 171.80 & 1.24 & 8.00 \\
\hline & $\mathrm{F}-\mathrm{G}-\mathrm{F} 2$ & 5.55 & 0.60 & 8.14 & 166.30 & 1.23 & 6.29 \\
\hline & $\mathrm{F}-\mathrm{G}-\mathrm{F} 3$ & 8.38 & 0.87 & 8.03 & 195.47 & 1.19 & 6.64 \\
\hline & $\mathrm{F}-\mathrm{G}-\mathrm{F} 4$ & 4.85 & 0.49 & 8.37 & 164.87 & 1.20 & 8.64 \\
\hline & $\mathrm{F}-\mathrm{G}-\mathrm{F} 5$ & 5.35 & 0.58 & 8.18 & 174.73 & 1.22 & 7.96 \\
\hline & $\mathrm{F}-\mathrm{G}-\mathrm{F} 6$ & 5.53 & 0.60 & 8.20 & 147.23 & 1.30 & 4.14 \\
\hline & Mean & 5.91 & 0.63 & 8.18 & 170.07 & 1.23 & 6.94 \\
\hline & S.D. & 1.25 & 0.13 & 0.11 & 15.70 & 0.04 & 1.64 \\
\hline & Significant difference & B & A & $\mathrm{B}$ & A & $\mathrm{A}$ & $\mathrm{B}$ \\
\hline
\end{tabular}

on the slope with the $\mathrm{G}-\mathrm{F}-\mathrm{G}$ vegetation pattern. However, there were no significant differences among vegetation patterns for $\mathrm{N}_{\text {mic }}(P<0.05)$.

In order to understand how different vegetation types at different slope positions affect the soil microbial biomass, we analyzed the distribution of $\mathrm{C}_{\text {mic }}$ and $\mathrm{N}_{\text {mic }}$ along the slope (Fig. 2). We divided the hill slope into upper, middle, and lower parts and used the means of two sampling sites for each slope position (for the lower slope of $\mathrm{G}-\mathrm{F}-\mathrm{G}$, there was only one site's data available). The vegetation type was the same at each slope position for F and G slopes, but the planted forest and the grass were distributed in different slope positions for the $\mathrm{F}-\mathrm{G}-\mathrm{F}$ and $\mathrm{G}-\mathrm{F}-\mathrm{G}$ patterns. The four vegetation patterns showed different trends from the upper slope to the lower slope. For the slopes with a single type of vegetation, $\mathrm{C}_{\text {mic }}$ and $\mathrm{N}_{\text {mic }}$ decreased from the upper slope to the lower slope under F but increased under G. For the slopes with a combination of grass and forest the $\mathrm{C}_{\text {mic }}$ and $\mathrm{N}_{\text {mic }}$ concentrations were higher at the middle slope for $\mathrm{G}-\mathrm{F}-\mathrm{G}$ and lower at the middle slope for $\mathrm{F}-\mathrm{G}-\mathrm{F}$.

3.3 Soil microbial functional diversity under different vegetation patterns

AWCD was used as an indicator of microbial activity in soil (Garland and Mills 1991). The curves for color 


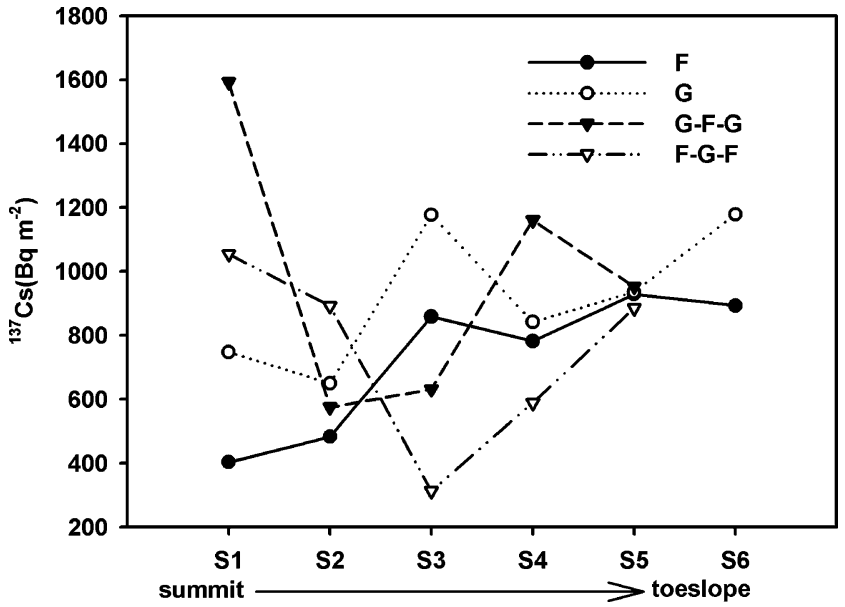

Fig. 1 Concentrations of ${ }^{137} \mathrm{Cs}$ under different slope positions for four vegetation patterns. $S 1-S 6$ indicate sampling sites 1-6 from summit to toe slope along the hill slope; $F$ forest, $G$ grass, $G-F-G$ grass on the upper and lower slopes and forest on the middle slope, $F-G-F$ forest on the upper and lower slopes and grass on the middle slope

development during the incubation period were sigmoidal, and the overall AWCD of $\mathrm{F}-\mathrm{G}-\mathrm{F}$ and $\mathrm{G}$ increased more rapidly than $\mathrm{F}$ and $\mathrm{G}-\mathrm{F}-\mathrm{G}$ after $24 \mathrm{~h}$ (Fig. 3). The $\mathrm{F}-\mathrm{G}-\mathrm{F}$ always had highest AWCD values before $120 \mathrm{~h}$ of incubation after which $\mathrm{G}$ exhibited much higher values.

The 96-h BIOLOG data were used to compute the Shannon diversity index $\left(H^{\prime}\right)$. The mean values of $H^{\prime}$ ranged from 2.75 for $\mathrm{F}$ to 2.82 for $\mathrm{F}-\mathrm{G}-\mathrm{F}$, and no significant differences were detected among the four vegetation patterns (Table 2). Soil microbial functional diversity decreased from the upper slope to the lower slope for F, G, and F-G-F. However, the highest value of $H^{\prime}$ for $\mathrm{G}-\mathrm{F}-\mathrm{G}$ was at the middle slope.

Principal component analysis of the primary BIOLOG data was used to analyze site similarity and to identify substrate redundancy. The data matrix consisted of 23 rows representing the sites and 31 columns representing the substrates. The first two principal components account for $41 \%$ and $16 \%$ of the variance. The bi-plot rays representing the substrates were shown in Fig. 4. The rays were labeled with the numbers 2 to 32, corresponding to the 31 substrates. Substrate vectors that point in one direction are positively correlated. Negatively correlated substrate vectors point in opposite directions, and uncorrelated substrate vectors are orthogonal to one another (Yan et al. 2000). The direction of the rays was used to indicate substrates that were instrumental
Fig. 2 Soil microbial biomass carbon (a) and nitrogen (b) at different slope positions under different vegetation patterns. $F$ forest, $G$ grass, $G-F-G$ grass on the upper and lower slopes and forest on the middle slope, $F-G-F$ forest on the upper and lower slopes and grass on the middle slope

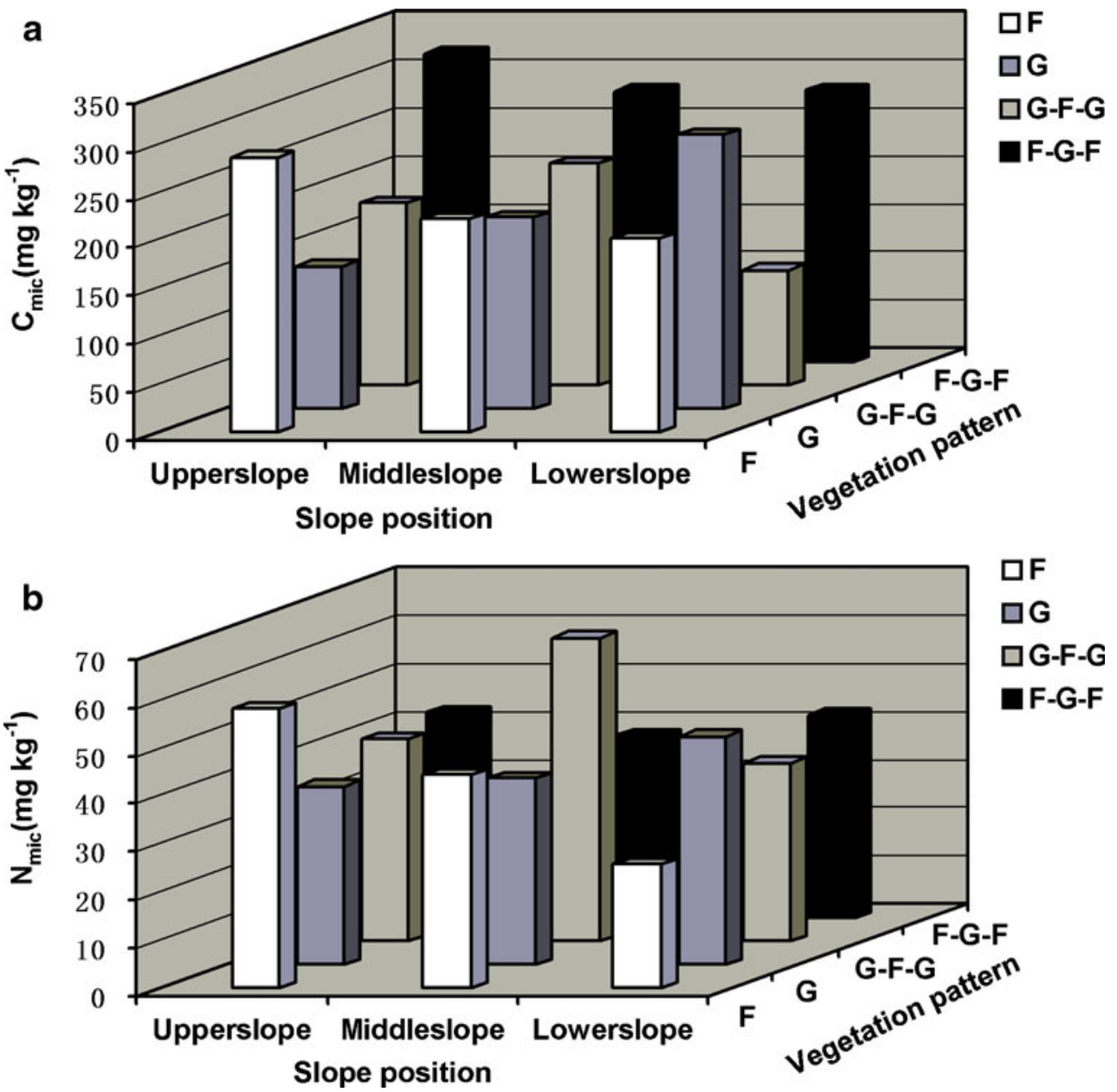




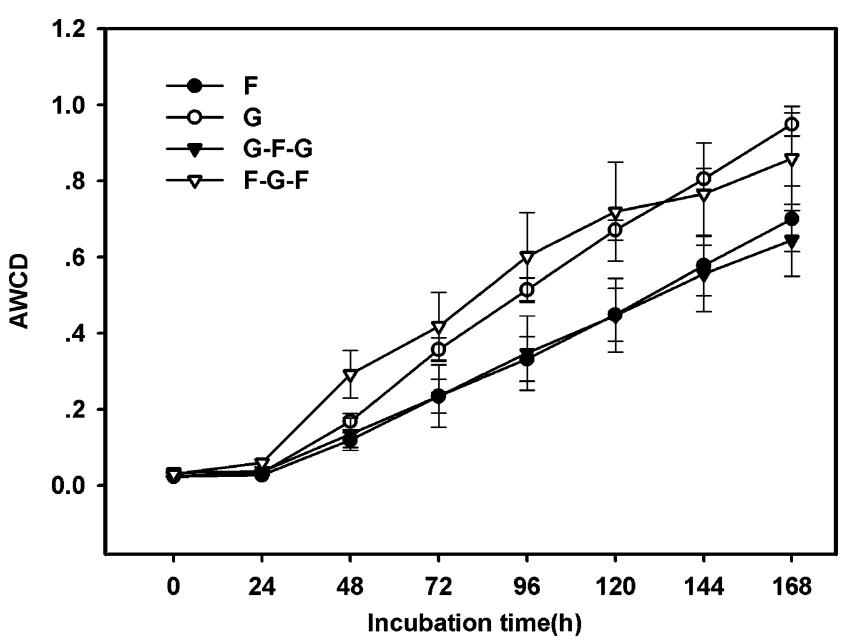

Fig. 3 AWCD of $31 \mathrm{C}$ sources for different vegetation patterns. The error bars indicate SE. $F$ forest, $G$ grass, $G-F-G$ grass on the upper and lower slopes and forest on the middle slope, $F-G-F$ forest on the upper and lower slopes and grass on the middle slope

in differentiating the sites. The microbial communities in samples from sites that were plotted on the far left of the graph did not always metabolized substrates for which the rays extended to the far right. Substrates that were utilized by all samples were located at the origin of the graph. The separation of sites indicated differences in the variety and number of substrates used. The sites with a single vegetation type, especially $\mathrm{G}$, are compactly clustered in the plane, showing that from the summit to toe slope, soil microbial communities had similar patterns of carbon substrate utilization. The variance among these sites was small. The $\mathrm{F}-\mathrm{G}-\mathrm{F}$ and $\mathrm{G}-\mathrm{F}-\mathrm{G}$ sites were scattered on the graph, indicating differences in substrate utilization among sites. The distance between the points for the four vegetation patterns indicated their similarity in substrate utilization. The greater the distance between points the more significant the difference between them.

In order to identify carbon substrates that significantly differentiated the four vegetation patterns; the analysis of variance was performed on the averaged site response of the four vegetation patterns for each substrate. The results

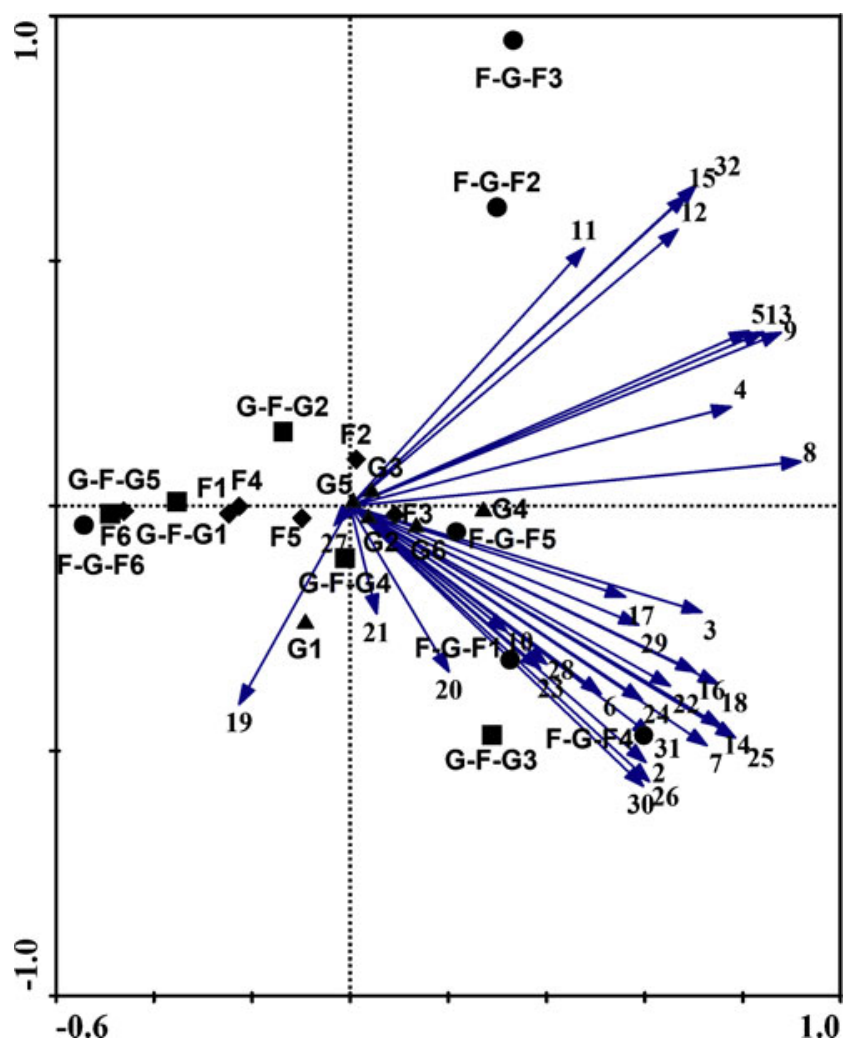

Fig. 4 Bi-plot showing the positions of the 31 substrates and the sampling sites in the plane of the first two principal components. Numbers $1-6$ indicate different sampling sites from the summit to the toe slope along the hill slope. $F$ forest, $G$ grass, $G-F-G$ grass on the upper and lower slopes and forest on the middle slope, $F-G-F$ forest on the upper and lower slopes and grass on the middle slope

showed that 11 carbon substrates were useful in detecting significant differences between the four vegetation patterns. Significant differences were mainly found between $\mathrm{F}-\mathrm{G}-\mathrm{F}$ and $\mathrm{F}$ and between $\mathrm{F}-\mathrm{G}-\mathrm{F}$ and $\mathrm{G}-\mathrm{F}-\mathrm{G}$. The discriminating substrates included five carboxylic acids, one amino acid, one amine/amide, and three polysaccharides. Since the microbial communities in all samples utilized all of these carbohydrates, no carbohydrate substrate on the plate significantly differentiated the four vegetation patterns.

Table 2 Soil microbial functional diversity values for four vegetation patterns

\begin{tabular}{lcccccc}
\hline Vegetation pattern & Upper slope & Middle slope & Lower slope & Mean & SD & Significant difference \\
\hline F & 2.90 & 2.78 & 2.57 & 2.75 & 0.197 & A \\
G & 2.84 & 2.76 & 2.71 & 2.77 & 0.074 & A \\
G-F-G & 2.67 & 2.85 & 2.79 & 2.77 & 0.145 & A \\
F-G-F & 2.97 & 2.77 & 2.73 & 2.82 & 0.344 & A \\
\hline
\end{tabular}

Different capital letters in the same column indicate significant differences at the 0.05 level among the vegetation patterns

$F$ forest, $G$ grass, $G-F-G$ grass on the upper and lower slopes and forest on the middle slope, $F-G-F$ forest on the upper and lower slopes and grass on the middle slope 


\section{Discussion}

4.1 Effects of different vegetation patterns on soil microbial biomass and soil microbial functional diversity

Significant differences in soil microbial properties among the four vegetation patterns were observed. The $\mathrm{F}-\mathrm{G}-\mathrm{F}$ slope had the highest $\mathrm{C}_{\text {mic }}$, microbial activity and microbial functional diversity, and the $\mathrm{G}-\mathrm{F}-\mathrm{G}$ had highest $\mathrm{N}_{\text {mic }}$. For this study area, previous study has indicated that a pattern of crop, grass, and woodland distributed from lower slope to upper slope before the abandonment of crop cultivation provided better conservation of nutrients. Vegetation patterns had different effects on soil physicochemical properties (Fu et al. 2000). Now, our results pointed out that microbial biomass and functional diversity also differed under different vegetation patterns.

Vegetation patterns can impact soil microorganisms through plant growth itself, as different vegetation types and growth status on different slope positions could directly impact the supply of available nutrients such as root secretions and dead plant materials for the growth of soil microorganisms. Waid (1999) reported that vegetation type, quantity, and chemical composition might influence soil microbial diversity. There are differences in both quantity and quality of residues that are returned to soil by different plant species (Wardle et al. 2004). Our results also indicated that the planted forest and grass at the same slope position had different effects on soil microbial biomass. Principal component analysis showed that on slopes with a single type of vegetation the soil microbial community utilized similar substrates from the summit to the toe, while variation in substrate utilization was apparent among sites on slopes that had a combination of forest and grass. These results also answer the question of whether or not two vegetation types provide a greater range and more diverse substrates for soil microorganisms than the single vegetation types on the hill slopes.

In addition, in the typical erosion-prone region vegetation patterns could affect soil microorganisms indirectly by influencing soil erosion processes. Differences in vegetation types along the entire slope, and differing vegetation types in each of the slope positions on the hill slopes, could induce different soil erosion (Fu et al. 2009), and soil erosion could result in secondary distribution of soil nutrients. Our results have suggested that the vegetation type planted on the upper slope had direct impacts on the middle and lower slope positions. Overall, the planted forest had higher microbial biomass and microbial functional diversity than grass, especially on upper slopes. However, when the same forest was present on the upper slope, there was no apparent difference in microbial biomass and functional diversity between forest and grass at the middle slope position. We, therefore, concluded that $\mathrm{F}-\mathrm{G}-\mathrm{F}$ was the best vegetation pattern to improve microbial biomass and microbial functional diversity. These results may correlate with the different soil erosion process induced by different vegetation types and distribution on different slope positions.

4.2 The impact of soil physicochemical properties and soil erosion on soil microbial properties

Vegetation restoration could improve soil quality and affect the soil ecosystem, especially soil microorganisms, by influencing soil moisture, temperature, $\mathrm{pH}$, carbon, and total nitrogen (Paul and Clark 1989). In this study, the physical and chemical soil characteristics showed in Table 1 were correlated with microbial biomass and microbial functional diversity for the four vegetation patterns (Table 3). Significant correlations exist between soil physicochemical properties and microbial properties $(P<0.05)$. The results indicated that $\mathrm{C}_{\text {mic }}$ was positively correlated with $\mathrm{TN}$ and $\mathrm{EC}$

Table 3 Correlations between soil microbial properties, soil physicochemical properties, and soil erosion

\begin{tabular}{|c|c|c|c|c|c|c|c|c|c|c|}
\hline & $\mathrm{C}_{\text {mic }}$ & $\mathrm{N}_{\text {mic }}$ & $H^{\prime}$ & SOC & $\mathrm{TN}$ & $\mathrm{BD}$ & SWC & $\mathrm{pH}$ & $\mathrm{EC}$ & ${ }^{137} \mathrm{Cs}$ \\
\hline $\mathrm{C}_{\text {mic }}$ & 1 & $0.606^{* *}$ & 0.063 & 0.234 & $0.460 *$ & 0.243 & -0.125 & $-0.474 *$ & $0.430^{*}$ & -0.151 \\
\hline $\mathrm{N}_{\text {mic }}$ & & 1 & 0.214 & $0.702 * *$ & $0.828 * *$ & -0.2 & 0.115 & -0.278 & $0.460 *$ & -0.252 \\
\hline$H^{\prime}$ & & & 1 & 0.037 & 0.032 & $-.420^{*}$ & $0.515^{*}$ & 0.012 & 0.262 & $-0.490^{*}$ \\
\hline SOC & & & & 1 & $0.947 * *$ & -0.336 & 0.046 & 0.01 & 0.221 & $0.562 *$ \\
\hline $\mathrm{TN}$ & & & & & 1 & -0.278 & -0.002 & -0.192 & 0.29 & $0.541^{*}$ \\
\hline $\mathrm{BD}$ & & & & & & 1 & 0.164 & -0.149 & 0.168 & $0.793 * *$ \\
\hline SWC & & & & & & & 1 & -0.151 & $0.467 *$ & 0.022 \\
\hline $\mathrm{pH}$ & & & & & & & & 1 & $-0.607 * *$ & 0.384 \\
\hline $\mathrm{EC}$ & & & & & & & & & 1 & $-0.504^{*}$ \\
\hline
\end{tabular}

$* P=0.05 ; * * P=0.01$

$C_{\text {mic }}$ microbial biomass carbon, $N_{\text {mic }}$ microbial biomass nitrogen, $H^{\prime}$ Shannon diversity, $S O C$ soil organic carbon, $T N$ total nitrogen, $B D$ bulk density, $S W C$ soil water content, $E C$ electrical conductivity 
and negatively correlated with $\mathrm{pH}$ and that $\mathrm{N}_{\text {mic }}$ was positively correlated with SOC, TN, and EC. Some existing studies have shown that soil microbial biomass carbon is positively correlated with soil organic carbon (Schnürer et al. 1985), but other studies have reported that most soil microorganisms respond rapidly to a decrease in nonliving organic nutrient matter in the soil (Potter and Meyer 1990). As $\mathrm{pH}$ is an important impact factor for microorganisms, the alkaline soil environment in our study area could negatively impact the microorganisms. This might be one explanation why the G-F-G samples had higher soil nutrient concentrations but lower $\mathrm{C}_{\text {mic }}$. Microbial functional diversity was positively correlated with SWC and negatively correlated with BD. SWC appeared to be the main factor influencing microbial functional diversity in this semiarid region. This is consistent with the results of Schimel (1995) who reported that drought might be the main factor reducing soil microbial community diversity and activity in semiarid areas. Drought may decrease substrate diffusion and increase the requirements of microorganisms for carbon and nitrogen. However, we found no significant correlation between soil microbial biomass and microbial functional diversity or between SOC and microbial functional diversity. This is in contrast with previous studies that had reported a positive relationship between microbial functional diversity and microbial biomass (Sharma et al. 1997) and between microbial functional diversity and soil organic carbon (Yan et al. 2000).

In the typical erosion-prone region, the vegetation patterns could induce different erosion processes and soil erosion may affect the soil physicochemical and biological properties. In this study, correlation analyses indicated positive relationship between ${ }^{137} \mathrm{Cs}$ concentration (which denotes degree of soil erosion) and soil physicochemical properties (see Table 3). The values of SOC, TN, and BD increased with increasing ${ }^{137} \mathrm{Cs}$ concentration, while EC decreased with as soil erosion could directly affect the distribution of SOC, TN, BD, and EC. These results were consistent with those reported by Li et al. (2006) who found that ${ }^{137} \mathrm{Cs}$ could be directly used to quantify dynamic soil organic carbon redistribution. ${ }^{137} \mathrm{Cs}$ and soil organic carbon were positively correlated. The light (i.e., low density) and fine (i.e., small size including clay and silt) fractions of soil are preferentially removed during soil erosion and soil organic carbon is concentrated in the surface soil and is of low density. Therefore, soil organic carbon is selectively removed by surface runoff and by wind erosion (Bajracharya et al. 2000; Lal 2003). However, this conflicts with the results of Hua et al. (2006), who found no significant correlation between ${ }^{137} \mathrm{Cs}$ and total nitrogen and concluded that total nitrogen was mainly impacted by vegetation itself.

There was no significant correlation between ${ }^{137} \mathrm{Cs}$ and microbial biomass in our study (see Table 3). However, microbial biomass was positively correlated with soil nutrients, and soil erosion had a positive effect on the distribution of soil nutrients. Therefore, we considered soil erosion to have an indirect impact on soil microbial biomass through its effect on soil physicochemical properties. Nevertheless, there has been little research in environments with serious erosion to understand the relationship between ${ }^{137} \mathrm{Cs}$ and soil microbial biomass, and the results are unclear. We observed a significant negative correlation between ${ }^{137} \mathrm{Cs}$ and soil microbial functional diversity $(P<0.05$; see Table 3$)$. It was difficult to understand why seriously eroded soils had higher microbial functional diversity. However, in the hilly area of the Loess Plateau, before vegetation restoration, intensive tillage was carried out on summits and foot slopes where the terrain was flat and soil erosion was less severe. Soil disturbance by tillage could have reduced microbial diversity (Lupwayi et al. 1998) due to desiccation, mechanical destruction, soil compaction, reduced pore volume, and disruption of access to food resources (Giller 1996).

\section{Conclusions}

The vegetation pattern had significant effects on soil physicochemical and biological properties. Compared to single vegetation types, the forest and grass combinations along slopes had more favorable soil microbial characteristics. $\mathrm{N}_{\text {mic }}$ was highest under the $\mathrm{G}-\mathrm{F}-\mathrm{G}$ vegetation pattern, and the $\mathrm{F}-\mathrm{G}-\mathrm{F}$ vegetation pattern had the highest $\mathrm{C}_{\text {mic }}$, soil microbial functional diversity, and activity.

Vegetation patterns could impact soil microorganisms through the influence on the soil physicochemical properties. Soil nutrients, particularly the TN, had direct effects on soil microbial biomass distribution, and SWC was the key factor impacting microbial functional diversity in this semiarid area. Our results also suggest that in the typical erosion-prone region, soil erosion could impact the distribution of soil nutrients and have an indirect effect on soil microbial biomass through its effect on soil physicochemical properties.

Acknowledgements We would like to express our gratitude to Dr. Ian R. Willett and Dr. Zhi Wang from Australia and USA for their valuable comments on the manuscript and the improvements of the English. We acknowledge the work of Mr. Yu Liu for collecting soil samples. This research project was funded by the National Basic Research Program (2007CB407205), the CAS/SAFEA International Partnership Program for Creative Research Teams of "Ecosystem Processes and Services," and the Chinese Academy of Sciences (KZCX2-XB2-05-03).

\section{References}

Bajracharya RM, Lal R, Kimble JM (2000) Erosion effects on carbon dioxide concentration and carbon flux from an Ohio Alfisol. Soil Sci Soc Am J 64:694-700 
Begon M, Harper JL, Townsend CR (1990) Ecology-individuals, populations, communities. Blackwell, Oxford

Bell T, Newman JA, Silverman BW, Turner SL, Lilley AK (2005) The contribution of species richness and composition to bacterial services. Nature 436:1157-1160

Bremner JM (1996) Nitrogen-Total. In: Sparks DL (ed) Methods of Soil Analysis. Part 3. Soil Science Society of America, Madison, pp 1085-1086

Brookes PC, Landman A, Pruden G, Jenkinson DS (1985) Chloroform fumigation and the release of soil organic nitrogen: a rapid direct extraction method to measure microbial biomass nitrogen in soils. Soil Biol Biochem 17:837-842

Bucher AE, Lanyon LE (2005) Evaluating soil management with microbial community-level physiological profiles. Appl Soil Ecol 29:59-71

Doran JW (1987) Microbial biomass and mineralizable nitrogen distributions in no-tillage and plowed soils. Biol Fertil Soils 5:68-75

Doran JW, Coleman DC, Bezdicek DF, Stewart BA (1994) Defining soil quality for a sustainable environment. Soil Science Society of America, Madison, pp 3-21

Fu BJ, Chen LD, Ma KM, Zhou HF, Wang J (2000) The relationships between land use and soil conditions in the hilly area of the loess plateau in northern Shaanxi, China. Catena 39:69-78

Fu BJ, Meng QH, Qiu Y, Zhao WW, Zhang QJ, Davidson DA (2004) Effects of land use on soil erosion and nitrogen loss in the hilly area of the Loess Plateau. Land Degrad Dev 15:87-96

Fu BJ, Wang YF, Lu YH, He CS, Chen LD, Song SJ (2009) The effects of land use combination on soil erosion-a case study in Loess Plateau of China. Prog Phys Geogr 33(6):793-804

Garland JL (1996) Patterns of potential C source utilization by rhizosphere communities. Soil Biol Biochem 28:223-230

Garland JL, Mills AL (1991) Classification and characterization of heterotrophic microbial communities on the basis of patterns of community-level sole carbon source utilization. Appl Environ Microbiol 57:2351-2359

Ge Y, Zhang JB, Zhang LM, Yang M, He JZ (2008) Long-term fertilization regimes affect bacterial community structure and diversity of an agricultural soil in northern China. J Soils Sediments 8:43-50

Giller PS (1996) The diversity of soil communities, the "poor man's tropical forest". Biodivers Conserv 5:135-168

Gobin A, Jones R, Kirkby M, Campling P, Govers G, Kosmas C, Gentile AR (2004) Indicators for pan-European assessment and monitoring of soil erosion by water. Environ Sci Policy 7:25-38

Gong J, Fu BJ, Li YM, Huang ZL, Huang YL, Peng HJ (2004) Effects of land use and vegetation restoration on soil quality in a small catchement of the Loess Plateau. Chin J Appl Ecol 15(12):22922296, in Chinese

Grayston SJ, Campbell CD (1996) Functional biodiversity of microbial communities in the rhizospheres of hybrid larch (Larix eurolepis) and Sitka spruce (Picea sitchensis). Tree Physiol 16:1031-1038

Green J, Bohannan BJM (2006) Spatial scaling of microbial biodiversity. Trends Ecol Evol 21:501-507

Harris JA (2003) Measurements of the soil microbial community for estimating the success of restoration. Eur J Soil Sci 54:801-808

Harris JA, Birch P (1989) Soil microbial activity in opencast coal mine restorations. Soil Use Manage 5:155-160

He JZ, Zheng Y, Chen CR, He YQ, Zhang LM (2008) Microbial composition and diversity of an upland red soil under long-term fertilization treatments as revealed by culture-dependent and culture-independent approaches. J Soils Sediments 8:349-358

He JZ, Ge Y, Xu ZH, Chen CR (2009) Linking soil bacterial diversity to ecosystem multifunctionality using backward-elimination boosted trees analysis. J Soils Sediments 9:547-554

Hill GT, Mitkowski NA, Aldrich-Wolfe L, Emele LR, Jurkonie DD, Ficke A, Maldonado-Ramirez S, Lynch ST, Nelson EB (2000) Methods for assessing the composition and diversity of soil microbial communities. Appl Soil Ecol 15:25-36
Hua L, Zhang ZG, Feng Y, Zhao H, Li JB, Wang XR, Zhu FY (2006) Soil erosion and losses of nitrogen and phosphorus by using ${ }^{137} \mathrm{Cs}$ tracer in the areas around Miyun reservoir. T CSAE 22(1): 173-178, in Chinese

Lal R (2003) Soil erosion and the global carbon budget. Environ Int 29:437-450

Li Y, Lindstrom MJ, Frielinghaus M, Bork HR (1999) Quantifying the spatial patterns of soil redistribution and soil quality on two contrasting hillslopes. In: Stott DE, Mohtar RH, Steinhardt GC (eds) (2001) Sustaining the global farm. Purdue University, West Lafayette, pp 556-553

Li Y, Poesen J, Yang JC, Fu B, Zhang JH (2003) Evaluating gully erosion using ${ }^{137} \mathrm{Cs}$ and ${ }^{210} \mathrm{~Pb} /{ }^{137} \mathrm{Cs}$ ratio in a reservoir catchment. Soil Tillage Res 69:107-115

Li Y, Zhang QW, Reicosky DC, Bai LY, Lindstrom MJ, Li L (2006) Using ${ }^{137} \mathrm{Cs}$ and ${ }^{210} \mathrm{Pbex}$ for quantifying soil organic carbon redistribution affected by intensive tillage on steep slopes. Soil Tillage Res 86:176-184

Lu RK (1999) Analytical methods for soil and agricultural chemistry. China Agricultural Science and Technology Press, Beijing

Lupwayi NZ, Rice WA, Clayton GW (1998) Soil microbial diversity and community structure under wheat as influenced by tillage and crop rotation. Soil Biol Biochem 30:1733-1741

Morin PJ, McGrady-Steed J (2004) Biodiversity and ecosystem functioning in aquatic microbial systems: a new analysis of temporal variation and species richness-predictability relations. Oikos 104:458-466

Nannipieri P, Ascher J, Ceccherini MT, Landi L, Pietramellara G, Renella G (2003) Microbial diversity and soil functions. Eur J Soil Sci 54:655-670

Pascual J, Garcia AC, Hernandez T, Moreno JL, Ros M (2000) Soil microbial activity as a biomarker of degradation and remediation processes. Soil Biol Biochem 32:1877-1883

Paul EA, Clark FE (1989) Soil microbiology and biochemistry. Academic, New York

Potter CS, Meyer RE (1990) The role of soil biodiversity in sustainable dryland farming systems. Adv Soil Sci 13:241-251

Schimel J (1995) Ecosystem consequences of microbial diversity and community structure. In: Chapin FS, Korner C (eds) Arctic and alpine biodiversity: patterns, causes, and ecosystem consequences. Springer, Berlin, pp 239-254

Schnürer J, Clarholm M, Rosswall T (1985) Microbial biomass and activity in an agricultural soil with different organic matter contents. Soil Biol Biochem 17:611-618

Sharma S, Piccolo A, Insam H (1997) Different carbon source utilization profiles of four tropical soils from Ethiopia. In: Insam H, Rangger A (eds) Microbial communities. Functional versus structural approaches. Springer, Berlin, pp 132-139

Smith LJ, Papendick RI (1993) Soil organic matter dynamics and crop residue management. In: Metting B (ed) Soil microbial ecology. Marcel Dekker, New York

Smith JL, Paul EA (1990) The significance of soil microbial biomass estimations. Soil Biochem 6:357-359

Staddon WJ, Duchesne LC, Trevors JT (1998) Impact of clear cutting and prescribed burning on microbial diversity and community structure in Jack pine (Pinus banksiana Lamb) clear-cut using Biolog-GramNegative microplates. World J Microbiol Biotechnol 14:119-123

Steenwerth KL, Jackson LE, Calderón FJ, Stromberg MR, Scow KM (2002) Soil microbial community composition and land use history in cultivated and grassland ecosystems of coastal California. Soil Biol Biochem 34:1599-1611

Vance ED, Brookes PC, Jenkinson DS (1987) An extraction method for measuring soil microbial biomass C. Soil Biol Biochem 19:703-707

Waid SJ (1999) Does soil biodiversity depend upon metabiotic activity and influences? Appl Soil Ecol 13:151-158 
Wang YB, Liu DY, Zhang L, Li Y, Chu L (2004) Patterns of vegetation succession in the process of ecological restoration on the deserted land of Shizishan copper tailings in Tongling City. Acta Bot Sin 46:780-787 (in Chinese)

Wardle DA, Bardgett RD, Klironomos JN, Setälä H, van der Putten WH, Wall DH (2004) Ecological linkages between aboveground and belowground biota. Science 304:1629-1633

White C, Tardif JC, Adkins A, Staniforth R (2005) Functional diversity of microbial communities in the mixed boreal plain forest of central Canada. Soil Biol Biochem 37:1359-1372

Xu ZH, Chen CR, He JZ, Liu JX (2009) Trends and challenges in soil research 2009: linking global climate change to local long-term forest productivity. J Soils Sediments 9:83-88
Xue S, Liu GB, Dai QH, Wu RJ (2008) Dynamic changes of soil microbial biomass in the restoration process of shrub plantations in loess hilly area. Chin J Appl Ecol 19(3):517-523, in Chinese

Yan F, McBratney AB, Copeland L (2000) Functional substrate biodiversity of cultivated and uncultivated A horizons of vertisols in NW New South Wales. Geoderma 96:321-343

Zak JC, Willig MR, Moorhead DL, Wildman HG (1994) Functional diversity of microbial communities: a quantitative approach. Soil Biol Biochem 26:1101-1108

Zhang L, Xu ZH (2008) Assessing bacterial diversity in soil. J Soils Sediments 8:379-388

Zheng FL (2006) Effect of vegetation changes on soil erosion on the Loess Plateau. Pedosphere 16:420-427 